\title{
RESEÑA AUDIOVISUAL
}

\author{
ARIA (2016). ÉMILIE JOUVET \\ Elixabete Imaz* \\ * Universidad del País Vasco/Euskal Herriko Unibertsitatea (UPV/EHU) \\ elixabete.imaz@ehu.es
}

\section{FICHA TÉCNICA \\ Título: Aria \\ Género: Documental \\ Dirección: Émile Jouvet \\ Nacionalidad: Francia \\ Duración: 60 minutos \\ Año: 2016}

Desde el escueto título sabemos que este documental tiene un final feliz. El film nos cuenta que la protagonista y directora Émilie Jouvet ha conseguido realizar su proyecto de ser madre a pesar de las restricciones que impone el estado francés a las mujeres solas y/o lesbianas. La prueba del final feliz es el título: Aria, que es el nombre que recibe de Jouvet su hija nacida por medio de tecnologías reproductivas y donante de semen, aunque la hija no aparezca durante todo el documental más que en forma de ecografía.

Se trata, como la misma Jouvet califica, de un film intimista y político, una reflexión sobre la parentalidad, y específicamente sobre la parentalidad queer, y sobre el deseo o no deseo de ser padre o madre. Grabado desde su iPhone en pleno periodo de embarazo, el documental se construye en su mayor parte a modo de breves monólogos en el que el vientre henchido por la gestación de Jouvet se convierte - recordando en ciertos aspectos a los usos de los confesionarios católicos - en el escenario idóneo para la introspección y el relato reflexivo. Una sucesión de representantes de diferentes sensibilidades del abanico queer, militantes y/o simpatizantes de la causa o simplemente amigos y amigas de la realizadora se turnan en encuentros recogidos e íntimos con el vientre de la directora, quien solo muy puntualmente interviene con alguna palabra y que se limita a grabar. Los y las participantes rodean el vientre, lo acarician, lo escuchan, lo palpan mientras los temas de cómo se percibe la paternidad, la maternidad, el deseo o no de tener un hijo o hija, el 
carácter de ese deseo o las dificultades de llegar a ser padre o madre queer en Francia se desgranan en pequeños monólogos sin formato de entrevista.

En este caso no voy a detenerme en la fetichización, veneración o incluso cierta idolatría que en determinados momentos transmiten esos cuerpos inclinados sobre el vientre gestante, que ciertamente implica, en mi opinión, una contradicción con la ampliación de la noción de parentalidad que parece proponer el film. La elección del vientre henchido como inspirador, testigo y escenario de las reflexiones sobre la parentalidad parecen reincidir en una imagen de la maternidad restrictiva en la que el vínculo biológico-fisiológico prima en la definición, y en la que la maternidad viene caracterizada principalmente por la gestación y el parto. Es posible que esta escenografía planteada por la directora no fuera tampoco del gusto de todos los participantes, pues unos pocos lo hacen fuera de este marco y eligen el fondo de su casa o un parque para la grabación.

Por el contrario, prefiero centrarme en los primeros, largos minutos, del film y en su estrategia narrativa que conmueve y empatiza al espectador o espectadora con la protagonista, la propia Émilie Jouvet, y a su vez con las mujeres que se encuentran en la misma circunstancia en Francia, la de querer ser madre sin pareja masculina. Y es que considero que lo más potente de este documental es lo que no se dice. No porque se oculte o se obvie, sino porque se representa desde una ausencia total de palabras y discursos.

Durante aproximadamente diez minutos, se repite un ciclo de imágenes que comienza con un mismo tren que se observa saliendo de una misma estación al alba, después pinchazos en el vientre - se adivina que de la realizadora-, pruebas de embarazo negativas $y$, por último, unos pies entre los que se escurren unas gotas de sangre menstrual que mancha el suelo de la ducha. Las mañanas se suceden, las diferentes tonalidades de la luz, de la vegetación, que adquiere el paisaje, nos sugieren el paso de las estaciones del año. Son imágenes silenciosas y opresivas. Estos primeros minutos representan los cinco años de intentos fallidos de reproducción asistida con donante (inseminación artificial o fecundación in Vitro, este aspecto no se llega especificar en el film) que precedieron al embarazo y posterior nacimiento de Aria, que por fin logró Jouvet. Estas imágenes casi mudas son salpicadas por, esta vez sí, nada silenciosas sino estruendosas manifestaciones contrarias a la formación de familias homosexuales -entre otras se recoge la sorprendente metáfora de los "niños playmobil" del diputado Jacques-Alain Bénisti en relación a los niños que se crearian en el seno de estas formaciones familiares 
que se apoyan en las tecnologías reproductivas ${ }^{1}-$. También imágenes de pancartas contrarias a la diversidad familiar que dibujan el contexto homofóbico que se instauro en Francia durante la discusión de la ley de matrimonio igualitario ("mariage pour Tous"). Estos primeros minutos del documental nos hablan de los cinco años de tentativas fallidas de la protagonista, de sus periódicos viajes a Bélgica en busca de una nueva inseminación o tratamiento, de sus solitarias inyecciones hormonales, de la menstruación que indica que tampoco en esta ocasión el tratamiento funcionó. Habla del desgaste económico y emocional, del ocultamiento y la soledad. Habla del asfixiante ambiente que rodeó esta sucesión de intentos fallidos de la protagonista, del ocultamiento, de la soledad, de la falta de apoyo normativo en un contexto que niega a las mujeres tener hijos por donante: "Tu n'as pas de droit" - "no tienes el derecho a ello"- resume concluyentemente Jouvet en un momento del documental.

A pesar del poco espacio que ocupan en este film, el peso de estas imágenes hace que sea comprensible la pertinencia del uso del término de "asilados reproductivos" que la directora hace, refiriéndose a sí misma y a las ciudadanas y ciudadanos franceses, en este caso, que deben buscar fuera de sus fronteras tratamientos $y / o$ procedimientos que les son negados en su país de origen ${ }^{2}$. El término de asilados es un término chocante, es cierto, y en una primera impresión podría considerarse un uso banal y hasta frívolo del mismo, aunque el visionado del documental logra hacer reconsiderar la pertinencia del término.

\footnotetext{
${ }^{1}$ En el debate sobre el matrimonio igualitario en el parlamento de Francia el diputado refiriéndose a la apertura de las técnicas de reproducción asistida a parejas lesbianas habló de "los niños playmobil que vamos a crear" L'OBS 3/02/2013 (/https://www.nouvelobs.com/politique/mariage-gay-

lesbienne/20130203.OBS7585/mariage-homo-de-la-pma-a-dsk-et-aux-enfants-

playmobil.html. Última consulta: 20/08/2018. Posteriormente el diputado se explicaba así: "J'expliquais qu'accepter la PMA (procréation médicalement assistée), c'est conduire à la GPA (gestation pour autrui), c'est ouvrir la boîte de Pandore. Or pour moi, choisir l'enfant qu'on veut, choisir une mère porteuse, négocier son ventre, c'est créer un enfant Playmobil, composer ainsi l'enfant que l'on souhaite en choisissant par exemple sa couleur de cheveux, comme dans ce jeu. Cette nouvelle loi, ce sont bien les enfants qui la subiront, or ils sont absents du débat." Le parisien, 4 de febrero de 2003. el http://www.leparisien.fr/val-de-marne-94/les-enfants-playmobil-du-depute-de-villierschoquent-le-ps-04-02-2013-2539389.php. Última consulta: 20/08/2018. La expresión niños playmobil fue ampliamente respondida y tachada de humillante para los hijos nacidos de este tipo de técnicas durante todo el periodo de debate de la Ley.

${ }^{2}$ Debate posterior a la presentación del film Aria en el festival Zinegoak 2018. Bilbao, 31/01/2018.
} 
En colaboración o conexión directa con estas imágenes iniciales, algunas de las intervenciones de personas contando sus experiencias respecto a su deseo de ser padres o madres resultan realmente conmovedoras: destaco la del transexual masculino que se resigna a no ser padre porque opta por no buscar por recovecos legislativos y en terceros países una posibilidad que su país -el país de la citoyenneté et des citoyens - le niega. O la pasmosa evidencia que nos hace ver una madre lesbiana al destacar que su proceso para ser madre no diferiría en nada de las preocupaciones, dudas, miedos, nerviosismos de las que puede tener cualquier pareja heterosexual al someterse a procedimientos de fertilización o fecundación a no ser por la pequeña diferencia de que estos segundos "sí tienen derecho", y por ello realizarán el tratamiento y seguimiento médico en su ciudad, con reembolso económico, con permisos en el empleo para acudir a las citas médicas mientras que la ausencia de ese derecho hace que en el caso de la mujer que nos habla deba desplazarse a otro país, sin permisos en el trabajo, ocultándolo, sin soporte del estado, sin reembolso económico. En estas intervenciones, de carácter más político, que, significativamente, son intervenciones que se hacen fuera del escenario inclinado sobre el vientre henchido, nos damos cuenta de que el film no solo está hablando del deseo de tener un bebé y de ser padre o madre sino que también es una propuesta de reflexión respecto a la extensión y contorno de los derechos reproductivos, sobre la capacidad del estado de decidir y gestionar en qué manera, cuándo y cómo gestionar nuestras capacidades reproductivas, entendiendo estas en sentido amplio de procreación y crianza..

El film mismo y la referencia de la directora a los asilados reproductivos contrasta de forma notable con otro término, el de turismo reproductivo, que ha ido arraigando y respecto al que tal vez nos posicionamos con poca cautela. El llamado turismo reproductivo engloba viajes de los padres y/o madres de intención en pos de lograr un tratamiento legal, técnica y/o económicamente inaccesible en su propio país. Tal y como apunta Ikemoto (2009: 278) en el relato habitual sobre el turismo reproductivo el perfil es el de una pareja o un individuo que empujado por un deseo de tener familia se aventura al fin del mundo en busca de ese bebé. El turismo reproductivo incluye la subrogación que se lleva a cabo en diversos países desde India a Estados Unidos donde el uso del término turismo se conjuga con la atribución de la libertad de las mujeres de disponer de sus capacidades reproductivas. Es decir, como en cualquier otra clase de turismo, los servicios prestados libremente redundan en beneficios para los proveedores, en este caso mujeres que consiguen mejorar su situación económica propia y familiar a la vez que posibilitan 
cumplir el sueño de los padres de intención. Pero las acepciones de turismo reproductivo son obviamente más amplias e incluyen también a España, que es mostrada a menudo como un destino preferido ${ }^{3}$ de personas en búsqueda de IA o FIV, pues aporta no solo calidad asistencial, apertura y a la vez rigurosidad legislativa, sino también toda una infraestructura hotelera y de servicios turísticos, en el que el tratamiento de fertilidad se convierte en unas auténticas vacaciones de sol y playa ${ }^{4}$. Así, en este uso del término, la movilidad en busca de fertilidad adquiere exactamente la acepción que le da el DRAE a turismo, es decir, la de "Actividad o hecho de viajar por placer".

Lo destacable de este documental, en mi opinión, es que con las imágenes que hemos descrito más arriba, junto con la reivindicación del término asilados políticos que hace Émilie Jouvet, se pone en evidencia la frivolización de los procesos por los pasan las personas que los practican en virtud de una falta de reconocimiento en sus países de derechos que sin embargo los países a los que recurren sí les reconocen. Es decir, que más allá de los deseos estamos hablando también de derechos y el término turismo, al que ahora nos hemos referido y que es cada vez más usado en el ámbito académico, oculta esa dimensión.

En la mayoría de los casos los derechos reproductivos son leídos en el sentido de capacidad de limitar o espaciar los hijos ${ }^{6}$. La falta de reconocimiento de

\footnotetext{
${ }^{3}$ Especialmente en tratamientos de inseminación artificial y fecundaciones in Vitro con donante. Así, en el relato de la protagonista del documental aquí reseñado, Bélgica se menciona junto con España como un posible lugar en el que las técnicas reproductivas negadas a las mujeres sin pareja masculina en Francia pueden ser practicadas.

${ }^{4}$ En hemeroteca véase por ejemplo: "España concentra hasta el 40 por ciento del turismo reproductivo", $A B C$ 31/07 2012; o "España, la perla del turismo reproductivo" El Mundo, 23 de mayo de 2015, o "Paquete de turismo reproductivo por 1000 euros" La Razón $12 / 06 / 2009$.

${ }^{5} \mathrm{http} / / /$ dle.rae.es/?id=axaWB7V. Última consulta: 15/08/2017.

${ }^{6}$ Sin embargo, la definición asumida actualmente por la ONU da pie a una consideración más extensa de los mismos. Así, el Programa de Acción de la Conferencia Internacional sobre Población y Desarrollo, celebrada en El Cairo en septiembre de 1994, da esta definición de los derechos reproductivos:

"Los derechos reproductivos abarcan ciertos derechos humanos que ya están reconocidos en leyes nacionales, documentos internacionales sobre derechos humanos y en otros documentos aprobados por consenso. Estos derechos se basan en el reconocimiento del derecho básico de todas las parejas e individuos a decidir libre y responsablemente el número de hijos, el espaciamiento de los nacimientos y a disponer de la información y de los medios para ello, así como el derecho a alcanzar el nivel más elevado de salud sexual y reproductiva. También incluye el derecho a adoptar decisiones relativas a la reproducción sin sufrir discriminación, coacciones o violencia, de conformidad con lo establecido en los documentos de derechos humanos."
} 
esos derechos reproductivos hizo que en las décadas de los setenta y ochenta muchas mujeres españolas viajaran para realizar abortos en Londres ${ }^{7}$. Eran viajes clandestinos para acogerse en el extranjero a un derecho que su país les negaba. Desde el prisma que nos plantea Jouvet, los paralelismos entre los viajes del documental y aquellos viajes a Londres son evidentes, aunque nadie se ha atrevido a llamar turismo a estos últimos.

En este punto me parece importante reproducir la consideración de Rickie Solinger (2002) sobre el desplazamiento que la defensa de los "derechos reproductivos" ha sufrido en los últimos años hacia la ideología de la "libertad de elección" en la reproducción. Hace 40 años, de la mano del feminismo, se reclamo con ahínco el derecho de las mujeres a tener el control sobre sus capacidades reproductivas, y es en ese sentido que se habló de derechos reproductivos. Hoy, existe cierto consenso respecto a la legitimidad de las mujeres para "elegir" buscar descendencia o no, cuándo y cuántos hijos/as tener. Si bien puede parecer que este deslizamiento contiene una continuidad lógica con aquella reclamación del movimiento feminista "prochoice" ("un hijo si yo quiero cuando yo quiero", reclamaban las manifestaciones pro derecho al aborto), esta autora sostiene que este desvío desde el discurso del "derecho reproductivo" al de la "libertad de elegir", remite a la ficción de la decisión como algo absolutamente personal que plantea las responsabilidades maternales como un asunto privado, y que implica que las mujeres deben asumir la responsabilidad derivada de su elección. Solinger se pregunta en qué medida quedan los derechos reproductivos de las mujeres enmascarados o cercenados al sustituir el término derecho por el de elección, pues mientras los derechos son algo de lo que una es titular, inherentes al ser mismo, elegir se refiere al privilegio de discriminar en el mercado entre varias opciones. En este giro conceptual, Solinger adivina el triunfo del privilegio de la consumidora sobre los derechos reproductivos de las mujeres (ibidem: 8). El desplazamiento desde el ámbito de la ciudadanía -ámbito de los derechos-al del consumo que escoge entre las distintas opciones de las que se dispone-, olvida los recursos diferenciados entre las mujeres por las que esa elección puede hacerse posible.

Programa de Acción de la Conferencia Internacional sobre Población y Desarrollo, El Cairo, Egipto, 5-13 de septiembre, 1994, Doc. de la ONU A/CONF.171/13/Rev.1 (1995). Sobre esta cuestión consúltese, por ejemplo, Jyoti Shankar (2001).

${ }^{7}$ Consúltese el histórico reportaje publicado en El País en el año 1976 y firmado por Neliana Tersigni. Reeditado en El País el 11 de julio de 2011. https://elpais.com/diario/2011/11/27/eps/1322378810_850215.html. Última consulta: 12/07/2018. 
Nociones como la de "turismo reproductivo" serian coherentes con esta idea de libertad de elegir, donde los padres de intención podrian optar entre las posibilidades que se les ofrecen para satisfacer sus deseos, eligiendo responsablemente según los recursos económicos, culturales, formativos etc. de los que dispongan. Desde esta perspectiva y sin abrazarme del todo a la noción de asilados reproductivos propuesta por Jouvet, sí que este documental hace percibir la necesidad de retornar a la noción de derechos reproductivos, redefiniendo sus contornos y desarrollando las distintas dimensiones que contiene -especialmente pensando en qué lugar otorgamos al deseo de ser padre y/o madre dentro de esos derechos-. Eso incluye renegar del concepto de turismo reproductivo, al que desde el mundo académico nos hemos abrazado tan acríticamente y que oculta la complejidad de relaciones, vínculos y desigualdades que se producen en la reproducción asistida. Una complejidad que queda encerrada entre, por una parte, el relato ingenuo y por momentos frívolo del deseo de formar una familia; por otra, la libertad de disponer de nuestras capacidades reproductivas como elemento intrínseco de los actos de donación; y por último, las lecturas opuestas que participan de la convicción de que las tecnologías reproductivas son exclusivamente relaciones de explotación.

\section{BIBLIOGRAFÍA}

Ikemoto, L. C. (2009). Reproductive Tourism; Equality Concerns in the Global market for Fertility services. Laweinequality: A journal of Theory and Practice, 27(2), 277-309.

Singh, J. S. (2001). Un nuevo consenso sobre población: balance y propuestas en el umbral del siglo XXI. Madrid: Icaria

Solinger, R. (2002). Beggars and Choosers, How the politics of choice shapes adoption, abortion, and welfare in the United States. Nueva York: Hill and Wang. 